\title{
Participatory approach for flood risk assessment: the case of Yeumbeul Nord (YN), Dakar, Senegal
}

\author{
B. $\mathrm{Sy}^{1}$, C. Frischknecht ${ }^{1}$, H. Dao ${ }^{2}$, G. Giuliani ${ }^{4}$, D. Consuegra ${ }^{1,3}$, \\ S. Wade ${ }^{5} \&$ C. Kêdowidé 6 \\ ${ }^{1}$ Department of Earth Sciences, University of Geneva, Switzerland \\ ${ }^{2}$ Department of Geography and Environment, \\ University of Geneva, Switzerland \\ ${ }^{3}$ School of Business and Engineering Vaud, Switzerland \\ ${ }^{4}$ Institute for Environmental Sciences, University of Geneva, Switzerland \\ ${ }^{5}$ Institute of Earth Sciences, University Cheikh Anta Diop, Senegal \\ ${ }^{6}$ African Urban Management Institute, Senegal
}

\begin{abstract}
Flooding has emerged lately as a major threat for poor people in the suburban area of Dakar (Senegal), a densely populated area. In this region, flood events are mainly controlled by rainfall intensity and groundwater level fluctuations.

To assess flood risk at a neighbourhood level, accurate data on flood extent, exposure and vulnerability is required. The objective of the present study is to obtain these data combining remote sensing data and local knowledge. Field work data were collected through interviews with inhabitants. About 500 respondents were surveyed with the support of a local association and very detailed mapping was carried out to clearly identify elements at risk.

Information collected at the household level concerns: 1) socio-economic data, 2 ) information on the property, 3) flooded houses and 4) strategies of risk reduction.

This research demonstrates that local knowledge is an important tool to obtain accurate data useful for understanding flood hazard and vulnerability patterns. It provides quantitative data at the household level that can be used to complement conventional GIS and remote sensing data.
\end{abstract}

Keywords: flooding risk, P-mapping, P-GIS, Dakar, Yeumbeul Nord (YN). 


\section{Introduction}

Natural disasters caused by natural phenomena, whether geological, hydrological and climate affect more and more people in the world with floods constituting the primary cause across the globe (Wang et al. [1]). In the period between 1900 and 2016, there were 910 flood disasters in Africa alone, killing 27,051 people, affecting 71 million people, and causing 7.9 million USD of economic losses (EMDAT [2]). For Senegal itself, in the past 30 years (1980 to 2009 inclusive) over 900,000 people were affected, 45 were killed, and damage costs were estimated to be more than 142 million USD (Gouvernement du Sénégal [3]). The Dakar region is the most affected region, where several severe floods occurred in 1989, 1996, 2001, 2005, 2009, and 2012, affecting particularly the suburbs, the 2009 event being the worst.

Many efforts have been tempted by the Government and local authorities to deal with and minimize the negative impacts of frequent floods, consisting of structural (construction of canalization and retention basins) and non-structural measures (relocation). But flooding within sub-urban of Dakar still represents a major problem for the local government. And the lack of information on hazard and vulnerability related to floods does not allow to produce quantitative assessment on flooding risk, necessary for the implementation of a flood risk reduction policy and a sustainable development.

Flood risk assessments are usually carried out by three approaches: 1) field work, 2) remote sensing analysis and/or 3) hydraulic modelling. As such, these approaches present some specific limitations, related either to the time required to carry out field work, weather conditions (Brivio et al. [4]) influencing the quality of satellite images or the lack of images covering the area and the uncertainties on results obtained by hydraulic modelling (Pappenberger et al. [5]), which is very sensitive to the accuracy of basic data. Therefore, the main purpose of this study is to obtain accurate data on flood risk related parameters combining remote sensing data and local knowledge. As mentioned by Tran et al. [6], local people have a better understanding of their surroundings and can help identify areas prone to floods. Moreover, it is also known that local knowledge can improve the accuracy of data (Dunn [7]). Therefore, a participatory approach has been used implying participatory mapping (P-mapping) and participatory GIS (P-GIS) in order to consider and integrate local knowledge on floods.

\section{Study area}

The area under investigation is the municipal district of Yeumbeul Nord (YN), one of the 16 municipal districts of the city of Pikine. It is located in the suburbs part of the capital city Dakar in Senegal (figure 1). The total area of this municipal district covers about $9 \mathrm{~km}^{2}$ divided into 82 major neighbourhoods (Kêdowidé and Cissé [8]). According to the 2013 census of the National Senegalese Agency for Statistic and Demography, the total population is about 168,379 inhabitants (ANDS [9]). It is one of the most populated districts of Senegal, with a population density of 
approximately 18,700 habitants $/ \mathrm{km}^{2}$. The study area is characterized by lowlands with elevations less than $20 \mathrm{~m}$.

Floods occurring in YN are due to the combination of natural (rainfall variability, groundwater position, topography, hydrology and lithology), and anthropogenic factors related to uncontrolled urbanization and soil impermeability (Mbow et al. [10]).

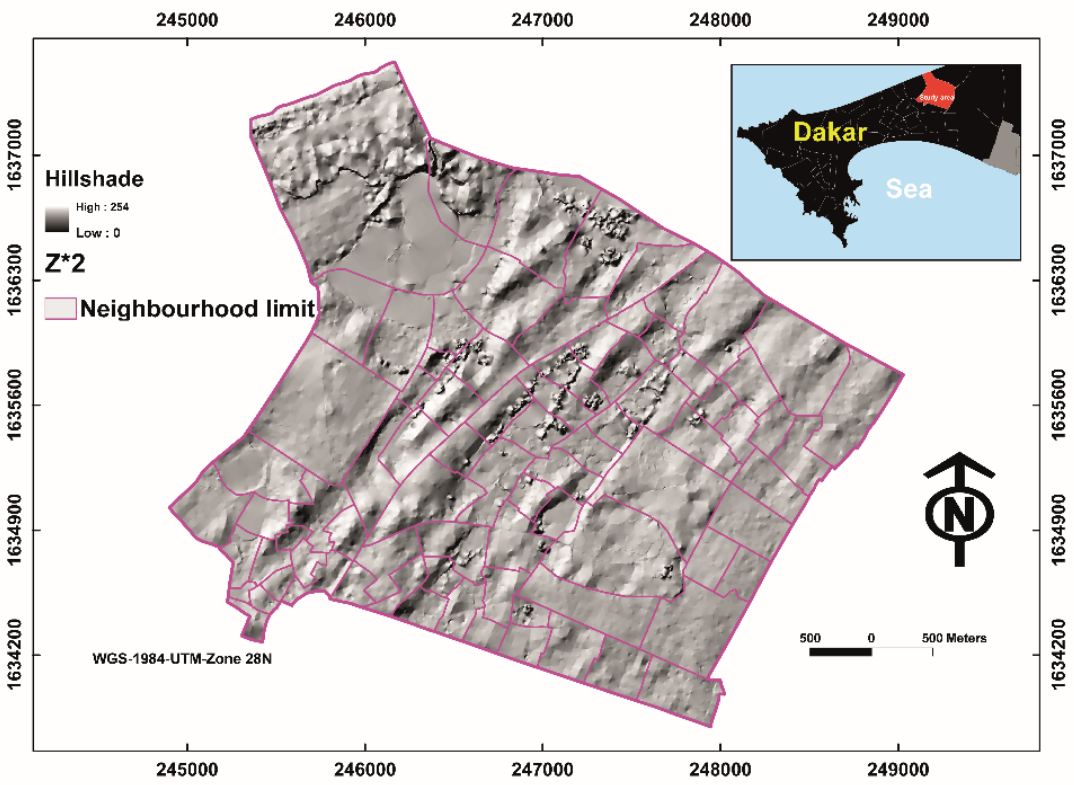

Figure 1: Map of Yeumbeul Nord and the 82 neighbourhoods.

\section{Methodology}

Acquisition of data related to floods in $\mathrm{YN}$ was achieved using remote sensing and ground based data (figure 2). Satellite data were used to obtain a preliminary landuse map including the spatial distribution of houses and the spatial distribution of the 2009 flood extent. Then, information was completed using local spatial knowledge. This has been achieved through active household survey and interviews, participatory-mapping and participatory-GIS. The interviews yielded socio-economics characteristics, physical exposure, flood depth and event duration, as well as strategies of flood risk reduction applied at the household level. In this study, the participatory approach refers to mapping and collecting information on flooding from the local population. P-mapping helped getting detailed location of elements at risk and areas of water. Finally, P-GIS was carried out in order to cross-check results obtained from the remote sensing data, interviews and P-mapping. 


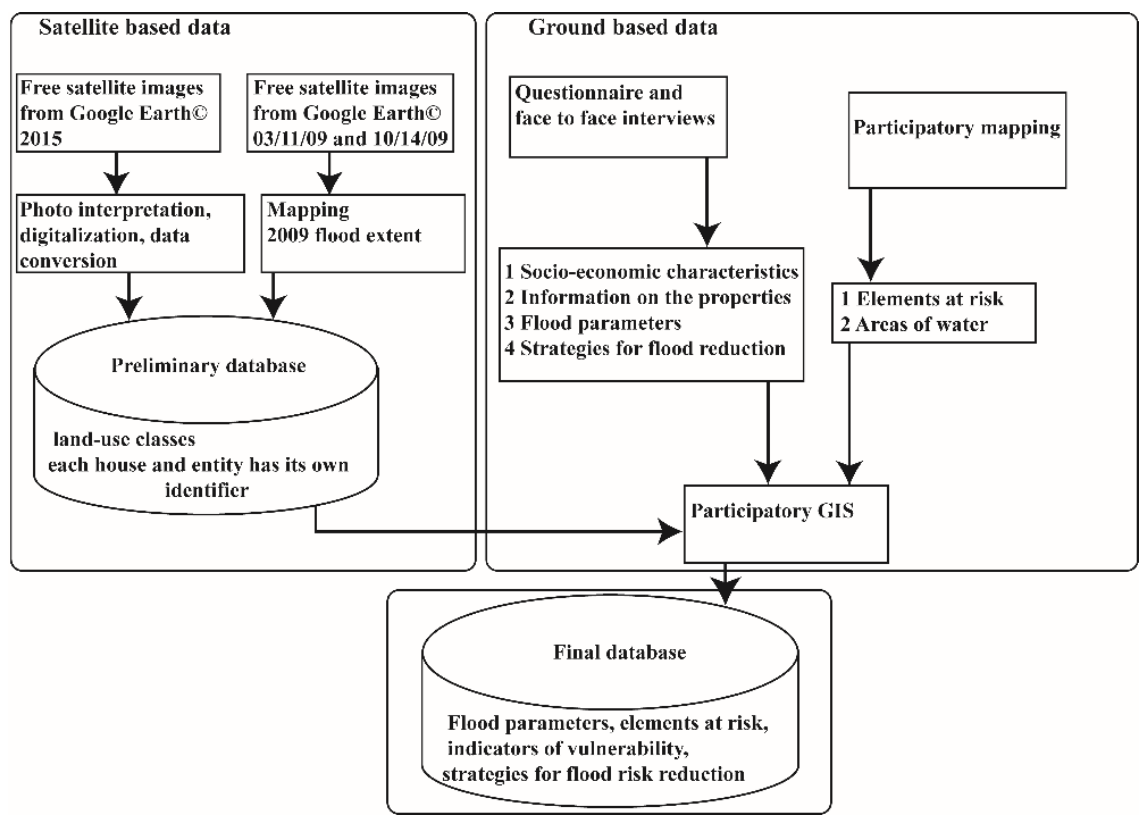

Figure 2: Chart flow of the data acquisition process.

\subsection{Remote sensing data}

In order to obtain our first land use map over the study area, we used high resolution satellite images (January-July, 2015) available on Google Earth $^{\circledR}$. The location of different land use categories (infrastructures, agricultural area, water bodies, etc.) and each house were photo-interpreted and digitized in Google Earth. We then used Global mapper $15^{\circledR}$ for the rapid conversion of the KML files into shapefiles with the reference system UTM (Zone 28N). Finally, we have imported our preliminary database in ArcGIS $10^{\circledR}$ where a unique identification number was attributed for each house.

The flood extent of the 2009 event has been obtained by comparing a reference high resolution satellite image before the flood (March 11) and after (October 14) obtained in Google Earth using its historical satellite dataset.

The Google Earth high-resolution imagery archive remains a largely unexploited resource for the analysis and description of the Earth's land surface (Potere [11]). The high-resolution images (2.5 m resolution) used in this analysis come from Digital Globe's (e.g. Quick Bird-Ikonos) satellites.

It can be seen in figure 3 that some areas are covered with clouds causing a partial loss of information. 


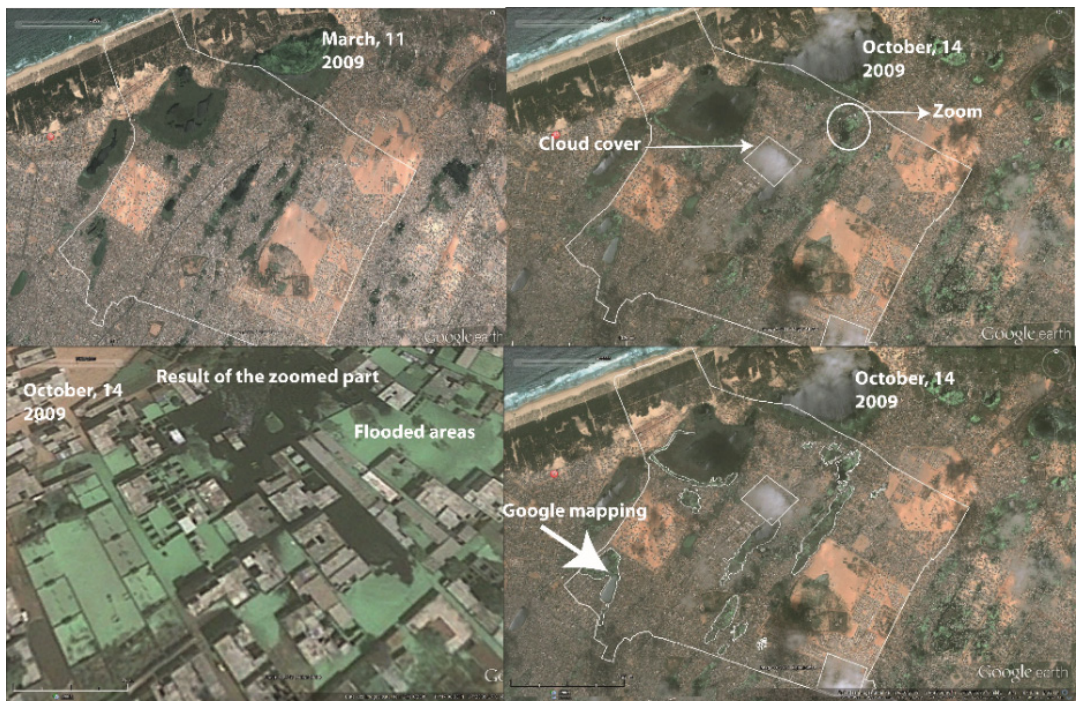

Figure 3: $\quad$ Free Google Earth ${ }^{\circledR}$ images used for flood extent mapping.

\subsection{Household survey}

Interviews were carried out on the basis of a questionnaire developed specifically for this study. It consisted of five main sections: 1) respondent's characteristics, 2) information on the property, 3) flooded houses, 4) socio-economic data and 5) strategies for flood risk reduction. The target of the interview was the household head and when the household head was not available, the spouse or a person having memories of the floods was surveyed. The questionnaires were conducted by teams composed of young adults from the local association "Réseau d'Information d'Education de Communication maternité de Yeumbeul" and the students from the Institute of Earth Sciences at the University of Dakar and each team was attributed to a specific neighbourhood for a total of 54. They were trained before going to the field.

Moreover, the questionnaire was first administrated in a test study lasting one day and implying 50 households. Feedback obtained from these participants and from the investigators allowed to ensure that wording was comprehensible and added other aspects not taken into account. In view of the low levels of education of respondents and the high illiteracy rate, the interviewers were called to translate the French version to the most widely spoken language in Senegal the Wolof. Each survey lasted 30 to $45 \mathrm{mn}$ during which the respondents actively interact with the investigators. Finally, 502 households were surveyed (figure 4).

In complement to the interviews, the respondents also provided information on the water depth affecting their house during the past flood events, when possible. With a handled GPS and the support of a paper map showing the details of each investigated neighbourhood, investigators were instructed to identify the house on the map and take GPS coordinates for cross checking. 


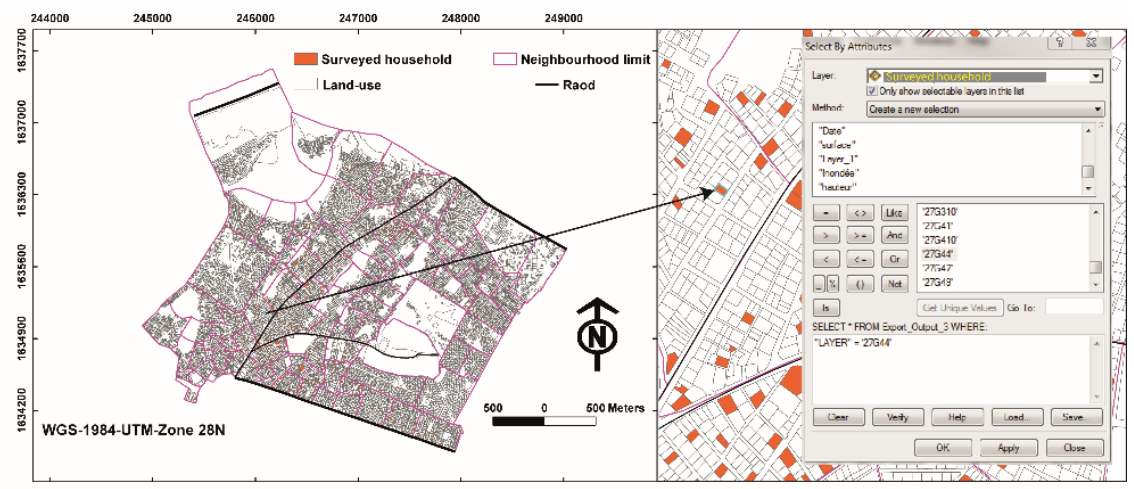

Figure 4: Distribution of the surveyed households.

\subsection{Participatory mapping and participatory GIS}

The P-mapping was carried out in the 82 neighbourhoods with the support of the local association and the householders interviewed. These local representatives brought their knowledge at three levels of the dataset. The first level was to verify the accuracy of the preliminary land-use map obtained with remote sensing data. The second level concerns the precise mapping of areas of water (lake, outlet, retention basin) and the third level was to achieve a detailed survey of important infrastructures of the area (e.g. health centres, schools, recreation areas, public service etc.). Handled GPSs, and mobile GIS were used to carry out the detailed mapping of the key infrastructures and water bodies. In complement to the update of the land use map, the data obtained on each household were combined with the GIS database existing on houses. To do this, the information gathered in the household survey was included into ArcGis $10^{\circledR}$ by joining the excel sheet containing the survey data and the initial GIS layer of houses based on a common identifier which was the name of the houses (each house had the same name in the Excel sheet and the initial database). This operation was carried out with the help of the interviewers in order to make sure that the merging of the two datasets was correctly done.

\section{Results}

\subsection{Land use}

The resulting land-use map of the study area was obtained from remote sensing data and then verified with the local teams and improved by integrating local knowledge. The result shows 7 major land cover types: forest, agriculture, buildings, infrastructures, water bodies, livestock farming, and recreation (figure 5). The area used for buildings and infrastructure is the largest with about $47 \%$. The other including roads, canalisations and the nature were estimated about $33 \%$. Water bodies were estimated about $10 \%$. The proportion of agriculture land is $5.8 \%$. Forest accounts for $3.6 \%$. The percentage of recreation area is 0.56 and 
livestock farming is 0.48 (table 1). This classification shows that the study area is highly urbanized.

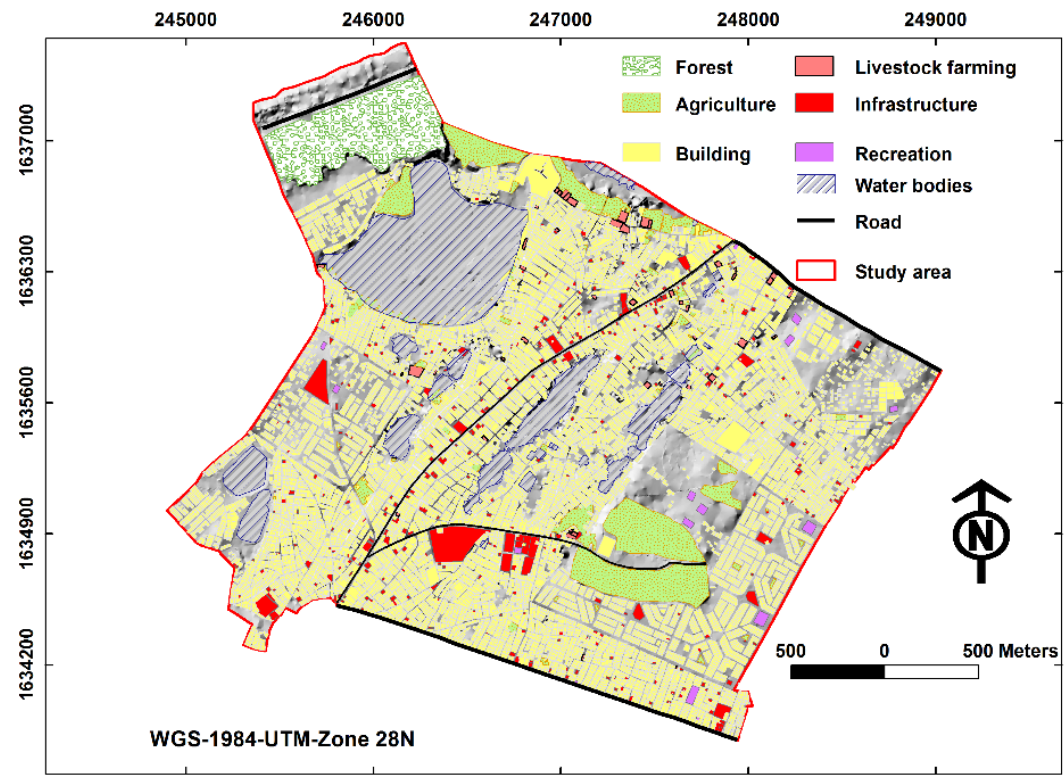

Figure 5: Land-use map.

Table 1: $\quad$ Land-use classes.

\begin{tabular}{|l|c|c|}
\hline Land-use & Area (ha) & Percent (\%) \\
\hline Forest & 30.67 & 3.6 \\
\hline Agriculture & 49.17 & 5.80 \\
\hline Buildings & 371.63 & 44.40 \\
\hline Infrastructure & 23.22 & 2.80 \\
\hline Water (lake-retention bassin-outlet) & 79.17 & 9.45 \\
\hline Livestock farming & 4.03 & 0.47 \\
\hline Recreation & 4.71 & 0.56 \\
\hline Others & 274.33 & 32.92 \\
\hline
\end{tabular}

\subsection{Flood extent}

Figure 6 presents the flood extent of the 2009 event based on remote sensing analysis and the flood extent that might have really occurred if we integrate the places highlighted by the household interviews for this event. This result demonstrates that household surveys can contribute to improve data provided by remote sensing, when the images is covered by clouds and also yield more accurate information. 


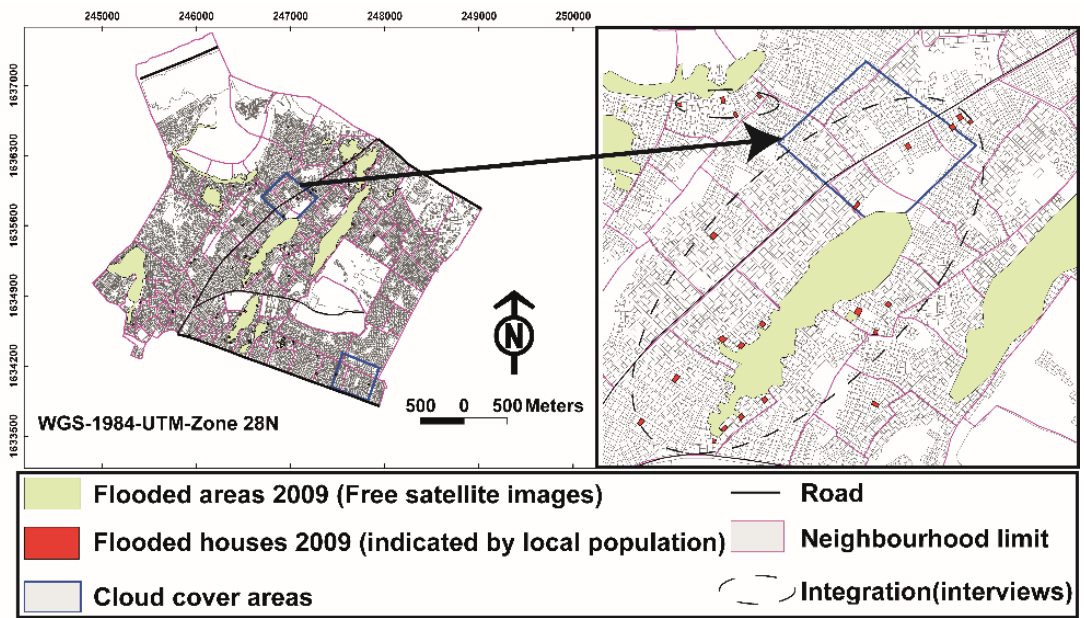

Figure 6: Flood extent based on remote sensing and P-mapping.

\subsection{Flood depth and flood duration}

During the survey, respondents were asked to show the depth reached by flood events and to describe the duration. Based on this information, we can see (figure 7) that the flood depth, independently of the event, varies from $0.2 \mathrm{~m}$ to $1 \mathrm{~m}$,

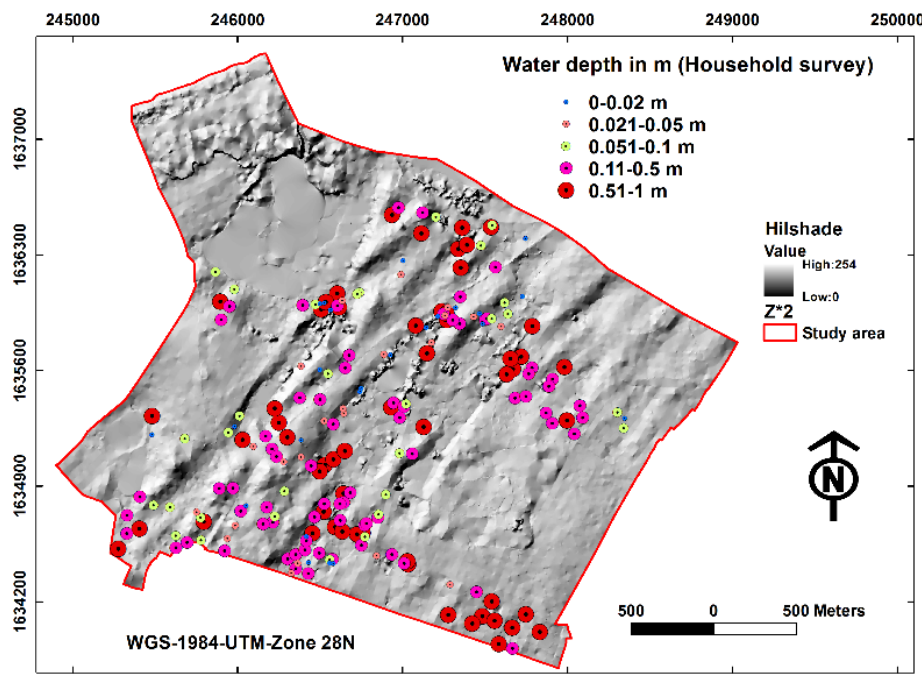

Figure 7: Spatial distribution of flood depths. 


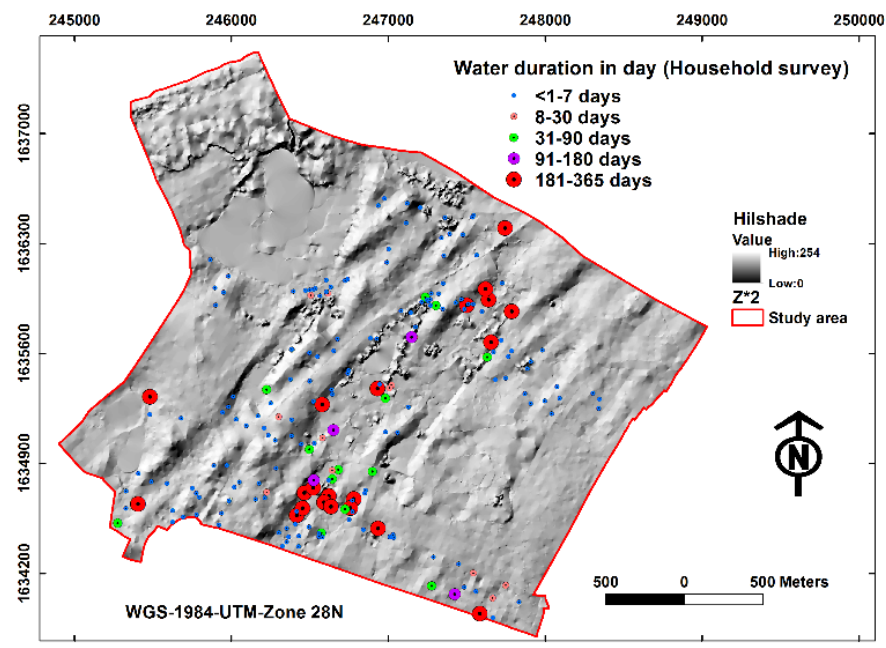

Figure 8: Spatial distribution of flood duration.

with an average of $0.5 \mathrm{~m}$, whereas the flood duration (figure 8) ranges from $<1$ day to 365 days. Such a long duration is probably due to the lack of means for water evacuation and the existence of topographic depressions (Mbow et al. [10]). But the usual water duration is between 0 and 7 days.

\subsection{Socio-economic characteristics of the household survey}

Table 2 summarizes the general demographic and social characteristics of the 502 households included in our sample. The majority of the respondents were women (67\%). Among the respondents $41 \%$ were the owner of the house and 59\% were not. Respondents were distributed among the following categories: $25 \%$ were the head of household, $36 \%$ were the spouse of head of household and $39 \%$ other were in general the most knowledgeable person in terms of flooding. The average number of persons per household is 13 . The average of number of women per household was 6 . The average number of disabled was 1 . The average number of children per household was 5. The age of the respondents varies from 15 to 87 and the average is 44 years old.

The analysis of household head education shows that $27 \%$ of the household head were illiterate, $18 \%$ had primary school level, and $14 \%$ had secondary school level, $6 \%$ had university level and $32 \%$ had received another type of education.

The average monthly income per household in YN is 435 USD.

\subsection{Information on the physical exposure}

The survey revealed key information on the 502 households related to date of construction, the ownership, the type of construction materials and the structure as well as the price of the land. Results show that $12 \%$ of the houses were built 
Table 2: Respondent's characteristics.

\begin{tabular}{|l|l|c|c|}
\hline Variable & \multicolumn{1}{|c|}{ Categories } & Number & Percent (\%) \\
\hline \multirow{3}{*}{ Gender } & Men & 165 & 33 \\
& Women & 336 & 67 \\
\hline \multirow{3}{*}{ Owner } & Yes & 206 & 41 \\
& No & 295 & 59 \\
\hline \multirow{3}{*}{ Statut } & Head of the household & 126 & 25 \\
& Spouse of the household & 181 & 36 \\
& Other & 194 & 39 \\
\hline
\end{tabular}

between 1970 and 1980, 40\% between 1981 and 2002 and 14\% between 2003 and $2015.65 \%$ of the surveyed households were living in their own houses, $20 \%$ were occupied by lodger and $15 \%$ by both owner and lodger. A majority of $88 \%$ of the surveyed houses were residential and $12 \%$ were mixed residential and workplace.

Almost all houses were built in cement and 34\% of the interior courtyards consist of cement, $29 \%$ of sand and finally $27 \%$ are in tile. More than $91 \%$ of the surveyed houses have a foundation and $2 \%$ do not know if there is or not. $67 \%$ of surveyed houses had cracks. $17 \%$ of surveyed houses were having the ground floor lower than the road.

The land surface occupied by houses varies from about $100 \mathrm{~m}^{2}$ to more than $300 \mathrm{~m}^{2}$. In terms of land price one third (36\%) costs less than 2000 USD (approx. $1 \mathrm{FCFA}=500 \mathrm{USD}$ ), $13 \%$ varies between $2001 \mathrm{USD}$ and $6000 \mathrm{USD}, 6 \%$ between 60001 USD and 12000 USD and 7\% above 12000 USD. 34\% of respondents do not know the land price of their house and 4\% didn't want to answer.

Among the 502 houses included in the surveyed, 209 were at least once flooded (figure 9). Most of surveyed houses were flooded in 2005, 2009, and 2012.

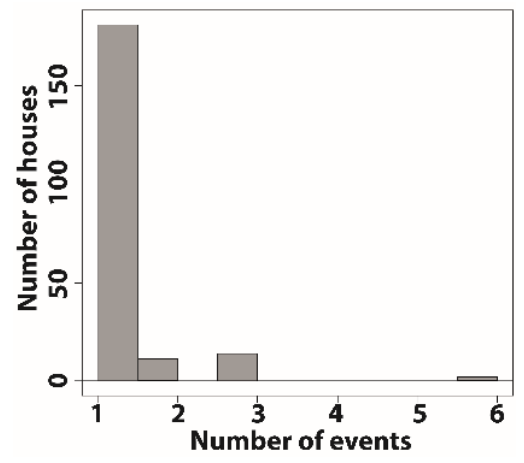

Figure 9: Number of events per house.

\subsection{Local strategies for flood risk reduction}

The household survey reveals the variety of local strategies put in place for flood risk mitigation. They can be classified in structural and non-structural measures as summarized in table 3 . 
Table 3: $\quad$ Flood risk mitigation.

\begin{tabular}{|l|l|}
\hline Types & \multicolumn{1}{|c|}{ Strategies of risk reduction } \\
\hline \multirow{4}{*}{ Stuctural } & Wall in front of the door of the house \\
\cline { 2 - 2 } & Stream deviation \\
\cline { 2 - 2 } & Cementing the courtyards of the house with slope \\
\cline { 2 - 2 } & Tilling the courtyards of the house with slope \\
\cline { 2 - 2 } & Piercing the walls \\
\cline { 2 - 2 } & Backfilling \\
\cline { 2 - 2 } & Building dikes using sand bags \\
\hline \multirow{3}{*}{ No structural } & Cleaning the canal \\
\cline { 2 - 2 } & Creation of association to fight against flooding \\
\hline
\end{tabular}

\section{Discussion and conclusion}

This study illustrated how the combined use of remote sensing data and local knowledge manages to capture key elements on flood hazard (the magnitude of flood: flood depth, flood duration), elements at risk (houses, critical infrastructures), vulnerability (socio-economic and physical vulnerability at the household level) as well as local strategies for flood risk reduction.

The innovative contribution of our investigation in comparison with previous works, such as Canevari-Luzardo et al. [12] and Musungu et al. [13] is the size of the survey, 502 households, and the level of details obtained on each flood risk parameters, in particular, detailed information on flood hazard. Moreover, we demonstrated how local knowledge can complement the use of remote sensing analysis, aspect that wasn't integrated in Canevari-Luzardo et al. [12] and Musungu et al. [13].

Although the participatory approach allowed us to improve the analysis of satellite images, it has some limitations. The local population can give inaccurate information, especially in terms of hazard mapping and spatial perception (Haynes et al. [14]). However in our study, we used neighbourhood scale paper maps, handled GPS and mobile SIG, therefore increasing the accuracy of mapping as already noticed by Canevari-Luzardo et al. [12]. In order to acquire high quality data, interviewers were trained, we organized a test study to ensure wording was comprehensible and we used the local language to avoid misunderstanding. However, the stability of the responses was not tested and it could be interesting to do so, in particular regarding flood events and their intensity.

In conclusion, our integration of local knowledge together with remote sensing shows that this can improve data, when satellite images are covered by clouds and also yield new or more accurate information in terms of hazard intensity, exposure and location of key infrastructures. Our approach is an alternative to the use of expensive high-resolution satellite images, when financial resources are scarce or when images are not available on the study area. While this study focuses on flood risk assessment, this approach could be replicated for different risks in other contexts. 


\section{References}

[1] Wang, Z., Lai, C., Chen, X., Yang, B., Zhao, S., and Bai, X., Flood hazard risk assessment model based on random forest, Journal of Hydrology, 527, pp. 1130-1141, 2015.

[2] EM-DAT, The international disaster database, http://www.emdat.be/ disaster_profiles/index.html, accessed 3 March 2016

[3] Gouvernement du Sénégal, Rapport d'évaluation des besoins post catastrophes: Inondations urbaines à Dakar en 2009. Gouvernement de la République du Sénégal avec l'appui de la Banque Mondiale, du système des Nation Unies et de la Commission Européenne, 2010.

[4] Brivio, P., Colombo, R., Maggi, M., and Tomasoni, R., Integration of remote sensing data and GIS for accurate mapping of flooded areas, International Journal of Remote Sensing, 23(3), pp. 429-441, 2002.

[5] Pappenberger, F., Matgen, P., Beven, K. J., Henry, J.-B., Pfister, L., and Fraipont de, P., Influence of uncertain boundary conditions and model structure on flood inundation predictions, Advances in Water Resources, 29(10), pp. 1430-1449, 2006.

[6] Tran, P., Shaw, R., Chantry, G., and Norton, J., GIS and local knowledge in disaster management: a case study of flood risk mapping in Viet Nam, Disasters, 33(1), pp. 152-169, 2009.

[7] Dunn, C. E., Participatory GIS-a people's GIS?, Progress in human geography, 31(5), pp. 616-637, 2007.

[8] Kêdowidé, C., and Cissé, O., Adapting to Flooding Impacts in Yeumbeul Nord, a Suburb of Dakar, Senegal. Institut Africain de Gestion Urbaine, 2013.

[9] ANDS, Recensement Général de la population et de l'Habitat, de l'Agriculture et de L'Elevage. République du Sénégal, Ministère de l'Economie, des Finances et du Plan, Agence Nationale de la Statistique et de la Démographie, 2014.

[10] Mbow, C., Diop, A., Diaw, A. T., and Niang, C. I., Urban sprawl development and flooding at Yeumbeul suburb (Dakar-Senegal), African Journal of Environmental Science and Technology, 2(4), pp. 75-88, 2008.

[11] Potere, D., Horizontal positional accuracy of Google Earth's highresolution imagery archive, Sensors, 8(12), pp. 7973-7981, 2008.

[12] Canevari-Luzardo, L., Bastide, J., Choutet, I., and Liverman, D., Using partial participatory GIS in vulnerability and disaster risk reduction in Grenada, Climate and Development, pp. 1-15, 2015.

[13] Musungu, K, Motala, S., and Smit, J., Using multi-criteria evaluation and GIS for flood risk analysis in informal settlements of Cape Town: the case of Graveyard Pond, South African Journal of Geomatics, 1(1), pp. 92-108, 2014.

[14] Haynes, K., Barclay, J., and Pidgeon, N., Volcanic hazard communication using maps: an evaluation of their effectiveness, Bulletin of Volcanology, 70(2), pp. 123-138, 2007. 